\title{
Graduate education quality evaluation research
}

\author{
Shuoyi He \\ The graduate school, Tianjin University of Finance And Economics, China
}

Keywords: Quality Evaluation; Graduate Education; Self-Assessment.

\begin{abstract}
Quality evaluation is foreign graduate education quality management is an important research content. In the United States, Britain and France as the research object, summarizes the developed countries the practice of the graduate education quality evaluation and the main characteristics, Combined with the positive study of the development of China's graduate education quality evaluation and the main problems and key in such aspects as evaluation subject, evaluation standard put forward the countermeasures of perfecting our country's graduate education quality evaluation system.
\end{abstract}

\section{Introduction}

Since the college expansion of 1999, the recruitment of students scale rapidly expansion of postgraduate education in our country. In 1999 the national graduate student recruit students 92000 people, to recruit students 631000 people, 2014, 15 years has increased by nearly seven times. The development of graduate student recruit students number poses challenges to the quality problem of the graduate student education. In the national medium and long-term education reform and development plan outline (2010-2020), under the guidance of state developed in recent years, the "opinions on deepening the reform of postgraduate education" (2013), "about strengthening degree and postgraduate education quality guarantee and monitoring system construction opinion" (2014) and other relevant documents, from the system of graduate education quality construction in our country, has been clear about the specific requirements. Can say, improve the quality is the focus of the graduate education reform and development faces in our country.

Graduate education has the scale development in China has gradually turned to the attaches great importance to the quality of security, accordingly, the graduate education quality evaluation has become our country graduate student education path of connotative development under the guidance of an important content. Graduate education quality evaluation is based on the nature of the postgraduate education and purpose, collect related information system, the quality of postgraduate education of value judgment, and then put forward the improvement measures, so as to promote the graduate education quality enhances unceasingly. Was investigated in the field of postgraduate education quality assurance representative of the United States, Britain, France, the experience and characteristics of graduate education quality evaluation, in combination with the new situation and new requirements of development of postgraduate education in China, so as to the continuous improvement of the graduate education quality evaluation system in our country and the development.

\section{The International Experience}

Because of the influence of different higher education management system, the world's graduate education quality evaluation presents different characteristics in the course of its development and experience.

The characteristics of American graduate education quality evaluation. In social evaluation as the main body. The United States is a free market economy countries, people emphasize democratic politics, more trust in non-governmental organizations. Americans are less dependent on the government to solve social problems, but rely on social organizations the power to solve. 
Otherwise, the United States higher education based on private higher education. American politics, economy, education situation makes American graduate education quality evaluation based on social evaluation as the main body, and social evaluating subject for all kinds of professional associations, academic groups and private organizations and other social organizations. Colleges and universities in the United States of self-evaluation of graduate education quality evaluation system plays a fundamental role.

The evaluation standard to standardized, scientific. Early American social evaluation organization is mainly in the graduate education such as academic degree thesis management, scientific research, teacher asked question to carry on the specification, the evaluation standard is not clear. With the development of graduate education, in order to adapt to the diversification of evaluation subject requirements, evaluation standard of evaluation subject enrichment, evaluation standard and more scientific, standardized, American graduate education quality evaluation system is increasingly perfect.

The characteristics of postgraduate education quality evaluation. Double evaluation in colleges and universities and government as the leading factor. The tradition of British university academic autonomy make university attaches great importance to the quality of education. Quality of graduate student education in the UK universities has a perfect internal evaluation system, the formation of a school, college, department of layered quality guarantee system, the university internal evaluation is institutional is strong, organized, hierarchical management of comprehensive quality evaluation system. The British government mainly through the external quality evaluation system to build indirectly participate in the graduate education quality evaluation, the graduate education quality evaluation results and the college of education funds, thus ensuring to undertake the important task of guarantee the quality of graduate education in colleges and universities. In addition, professional associations and academic groups can participate in the inspection and audit work of graduate education quality evaluation.

Diversified evaluation standards. Higher education in the UK, the early focus on university autonomy, which makes every universities have established their own quality evaluation standard, the unity is not strong. With the continuous development of graduate education, external quality assessment main body gradually involved in graduate education quality evaluation, evaluation standard unification gradually, and with a strong pertinence and effectiveness. , so to speak, the diversification of evaluation subject and evaluation ways to promote the UK graduate education quality evaluation standard of the development of diversified characteristics.

The characteristics of postgraduate education quality evaluation in France. The evaluation of government as the leading factor. France's education administration implement the unification of the highly centralized management. Centralized and determines the government in the predominant member of the graduate education quality evaluation. The French government grants, diploma awarded and control through the way such as identification, curriculum setting, personnel appointed directly involved in the graduate education quality evaluation, ensure quality of graduate education. Later, to adapt to European higher education pattern reform, the French government has established the intermediary nature of national assessment committee to be responsible for the quality evaluation, as well as encourage universities to self-assessment.

The evaluation standard is becoming more and more diverse. Founded in France in the $1980 \mathrm{~s}$ national assessment committee make its have the independent evaluation of government agencies, the agency is responsible for the evaluation system of colleges and universities, reviewing the status of subject construction and higher education. The 21st century, the social organization power in France the role of the graduate education quality evaluation gradually enhanced. These diverse evaluation form and evaluation main body makes French graduate education quality evaluation standard also gradually perfect.

\section{The Domestic Status Quo}

Graduate education quality evaluation in China starts late, 1985 years ago, our country's degree and postgraduate education is still in the early stage of development, it is not have the requirement of 
postgraduate education quality evaluation. In May 1985, in the second session of the state council degree committee, established at all levels to gradually establish a degree awarded quality inspection evaluation system, marks the building began implementing the graduate education quality evaluation system in our country. The graduate education quality evaluation system in our country is developing and perfecting.

At present, the graduate education quality evaluation of the government evaluation is given priority to, training units self-evaluation and social groups, non-governmental organizations, social evaluation needs to be further improved. But along with the increase in types of graduate education in our country, the government-led graduate education quality evaluation is more and more difficult to truly reflect the quality evaluation of objectivity, impartiality and efficiency. Overall, China's postgraduate education quality evaluation problems are as follows:

The evaluation main body lack of universality. A perfect quality evaluation system needs the participation of all parties related interests, the graduate student education is no exception. Long-term government evaluation of graduate education quality evaluation is more driven by executive order, have certain mandatory, ignored the assessment unit in the initiative and enthusiasm in the process of education evaluation. The existing social organizations of social evaluation activities are organized by government departments and colleges and universities, failed to fully reflect the actual demand of the society, also the lack of objectivity, this kind of evaluation is not called fully in the sense of social evaluation. Units of graduate student training in the practical work do not take the self-assessment, most colleges and universities still lack the graduate education quality evaluation system construction. Students graduate education quality is the vital interests of stakeholders, but the actual quality of graduate education evaluation are often ignored or even denied the right to graduate students to participate in.

Evaluation standard lack of diversity. Graduate education quality evaluation standard is a dynamic adjustment of concepts, with the development of graduate education and graduate cultivation model transformation and presents the characteristics of diversity. Graduate education in many colleges and universities of our country in the graduate education quality evaluation too much importance to the academic standards in the reasons, tend to ignore or do not take the actual unit of choose and employ persons emphasize practical, innovative talents selection standard, cause the college education of the graduate students cannot adapt to the employer's requirements. And in different areas, belonging to different types of graduate education unit, its graduate education quality evaluation standards tend to gm, attaches great importance to the commonness and ignore the targeted, but also not conducive to the produce of various units of graduate student training accuracy, high reliability of the graduate education quality evaluation results.

\section{Conclusion and Discussion}

Reconstruct and improve the graduate education quality evaluation system in our country, we must give full consideration to the domestic policy environment for the development of graduate education background, at the same time to absorb the developed countries in the development of graduate education quality evaluation is feasible, but not blindly follow the international practice. Scientific and effective system of graduate education quality evaluation, is required to build a set of scientific evaluation standard, to establish the government, training institutions and the social organization, unit of choose and employ persons, guidance teachers, graduate students, such as participation of multiple evaluation main body, should play a leading role in the evaluation of government, and to encourage self-evaluation of train units and attaches great importance to the social organization.

Graduate education quality evaluation standards should reflect the scientific nature and effectiveness. Units have a plenty of comprehensive universities of graduate student training in our country, have a plenty of financial, technical, normal, medical and other specialized colleges, have a plenty of university directly under the ministry of education, have a plenty of local university, have a plenty of key university, have a plenty of general university. Different nature, different types of training units of its postgraduate education development target, talent cultivation patterns and characteristics, education resources and environment, showing significant differences, we can't use a 
single standard for graduate education quality evaluation, otherwise it is easy to cause the graduate cultivation model of convergence and lost its own characteristics. Unit before the quality evaluation of graduate student training, therefore, should fully consider school talent training characteristics and realistic development of postgraduate education, and the design of the evaluation standard should not only meet the requirements of the graduate education evaluation standards of the state and characteristic.

Need special pointed out that in today's professional degree graduate education highly valued, the graduate education quality evaluation must be pay more attention to the professional degree graduate student talent training "applicability", "practical" characteristics, in setting up professional degree graduate education quality evaluation standard, in view of the social demand in the field of specific profession, introduced the evaluation of unit of choose and employ persons, because only the school develop the professional degree of unit of choose and employ persons is required for the society and gain recognition, professional degree postgraduate education can be healthy and persistent development.

With the rapid development of postgraduate education in our country, the social demand for high-level talents is increasing day by day, under the system logic of university governance, stakeholders have the right to put forward to the development of graduate education accountability, have the right to participate in the postgraduate education quality evaluation. Establish a government, training institutions and the social organization, unit of choose and employ persons, guidance of teachers, graduate students, graduate students education quality evaluation main body, accord with the requirement of modern management theory, but also the embodiment of the realization of modern university system in China.

First, our country academic degree system determines the government has the responsibility and power in the management and control of graduate education, the government should make evaluation on macro policies, guide the direction of evaluation. Second, and the role of self-assessment units of graduate student training to highly, not only to self-assessment as monitoring, management of graduate student education information feedback method, more self-assessment as to improve graduate education quality guarantee system, the important means to improve the quality of postgraduate cultivation of talents. The quality of graduate education to self-evaluation system through every link of graduate education, the content of the evaluation to a broad and specific, evaluation standards should be targeted. Third, make the professional education of social organizations involved in the graduate education quality evaluation, let professional people do professional thing, through the social organization of university rankings, accountability, etc., to the greatest extent to ensure the quality of graduate education evaluation fair and transparent. Fourth, the opinion of the social unit of choose and employ persons for graduate education in our country, especially in professional degree graduate education quality evaluation is an increasingly important factor. So, postgraduate education quality evaluation in our country should pay special attention to the social evaluation and feedback of unit of choose and employ persons. Fifth, in the "academic autonomy" concept, under the influence of teacher status in development of postgraduate education is more and more obvious. Instructor is one of the important participants and graduate student education practitioner, inspire teachers to participate in the postgraduate education quality evaluation, is helpful for mobilizing the enthusiasm of mentor, exercise their legitimate and necessary say, at the same time attaches great importance to the role of subject tutor group, in order to ensure the objectivity of the graduate education quality evaluation and fairness. Sixth, the graduate student is the direct stakeholders of the graduate education quality evaluation, the student to the education quality evaluation right feedback and reasonable proposal, the graduate education quality evaluation of the improvement of our country have a direct impact. Above graduate education quality evaluation of the main body is linked to each other, each other, and mutual supervision and checks and balances.

\section{References}

[1] Pan Wuling. Graduate education quality evaluation system research in China [D]. Shanghai: east China normal university, 2004. 
[2] Huang Baoyin, etc. We will accelerate the establishment of a sound degree and postgraduate education quality guarantee and supervision system in China [J] degree and postgraduate education, 2014 (3).

[3] Liu Peijun Employers evaluation: professional degree graduate education quality evaluation indicators necessary to the study of higher education, the heilongjiang province [J], 2013 (9).

[4] ZhanChunyan Tang Xinyan. International horizon, the graduate education quality evaluation based on the United States, Britain, France and Japan comparative study of the four countries [J] education development research, 2010 (21).

[5] XueEryongGraduate education quality evaluation of the strategy and method analysis [J] degree and postgraduate education. 2009 (6). 